\title{
FAKTOR - FAKTOR YANG MEMPENGARUHI KEJADIAN PEB PADA PASIEN RAWAT INAP DIRUANG ICU
}

\author{
Yuyun Setyorini, Martono, Imelda Wijayanti \\ Kementerian Kesehatan Politeknik Kesehatan Surakarta Jurusan Keperawatan
}

\begin{abstract}
Abstrack: Factor - The Influence Of Factors, Incidence Of PEB. ICU is and intensive room used to take care patients that need nursing and special treatment, on the critical condition and having a chance to be saved. The writer got the data from ICU RSUD Dr. Moewardi Hospital of Surakarta that there is an increastment of PEB victims from year 2010 to 2011 where the number of PEB victims on 2010 were 9 patients and on 2011 were were 79 patients. This study aims to clarify between the two dependent variables and independent through hypothesis testing at the time was past, so this type of research is to design Eksplantory Reserver retrospectively. The research was conducted by Chi Square test. There are not relation between factors that influence incident of $P E B$ to patient in treatment in ICU room of RSUD Dr. Moewardi Surakarta. There was no effect of the relationship between the incidence of PEB by a factor of gravida, distension of the uterus, a history of comorbid disease, maternal age and parity in patients hospitalized in the ICU Hospital Dr. Moewardi Surakarta.
\end{abstract}

Keywords: Factor - The Influence Of Factors, Incidence Of PEB

\begin{abstract}
Abstrak : Faktor - Faktor Pengaruh, Kejadian PEB. ICU adalah ruangan intensive yang digunakan untuk merawat pasien yang membutuhkan perawatan dan terapi kusus, dalam keadaan yang kritis serta kemungkinan dapat diselamatkan. Dari data yang diperoleh penulis di ruang ICU RSUD Moewardi Surakarta, jumlah angka kejadian pasien PEB ditahun 2010 sebanyak 49 pasien dan 79 pasien PEB ditahun 2011, sehingga mengalami kenaikan jumlah pasien PEB dari tahun 2010 - 2011. Tujuan penelitian ini untuk mengetahui faktor - faktor yang mempengaruhi kejadian Preeklamsi Berat pada pasien rawat inap. Penelitian ini bertujuan untuk menjelaskan antara dua variabel dependent dan independent melalui uji hipotesa pada waktu yang sudah lampau, sehingga jenis penelitian ini adalah Eksplantory Reserver dengan desain retrospectif. Penelitian ini dilakukan dengan uji Chi Square. Tidak ada pengaruh hubungan antara kejadian PEB dengan faktor gravida, distensi rahim, riwayat penyakit penyerta, usia ibu dan paritas pada pasien rawat inap di ruang ICU RSUD Dr. Moewardi Surakarta.
\end{abstract}

Kata Kunci : Faktor - Faktor Pengaruh, Kejadian PEB

\section{PENDAHULUAN}

Preeklampsia-eklampsia

merupakan kesatuan penyakit yang asih merupakan penyebab utama kematian ibu dan penyebab kematian perinatal tertinggi di Indonesia. Diagnosis dini preeklampsia yang merupakan pendahuluan eklampsia serta penatalaksanaannya harus diperhatikan dengan seksama. 
Pemeriksaan antenatal yang teratur dan secara rutin untuk mencari tanda preeklampsia yaitu hipertensi dan proteinuria sangat penting dalam usaha pencegahan, disamping pengendalian faktor-faktor predisposisi lain (Manuaba, 2005). Angka Kematian Ibu (AKI) Provinsi Jawa Tengah 2004 berdasarkan hasil survei kesehatan daerah sebesar 55,22 per 100.000 kelahiran hidup. Urutan penyebab kematian ibu dari yang terbanyak adalah perdarahan sesudah persalinan, pre eklamsi dan eklamsi, perdarahan sebelum persalinan, dan infeksi (Anonim, 2005).

Pada pre eklampsia terjadi spasme pembuluh darah disertai dengan retensi garam dan air. Pada biopsi ginjal ditemukan spasme hebat arteriola glomerulus. Pada beberapa kasus, lumen arteriola sedemikian sempitnya sehingga hanya dapat dilakukan oleh satu sel darah merah. Jadi jika semua arteriola dalam tubuh mengalami spasme, maka tenanan darah akan naik sebagai usaha untuk mengatasi tekanan perifer agar oksigenasi jaringan dapat dicukupi (Winkjosastro, 2000). Sedangkan kenaikan berat badan dan edema yang disebabkan oleh penimbunan air yang berlebihan dalam ruangan interstitial belum diketahui sebabnya, mungkin karena retensi air dan garam. Proteinuria dapat disebabkan oleh spasme arteriola shingga terjadi perubahan pada glomerulus (Winkjosastro, 2000). Pada preeklampsia yang berat dan eklampsia dapat terjadi perburukan patologis pada sejumlah organ dan sistem yang kemungkinan diakibatkan oleh vasospasme dan iskemia (Cunniangham, 2003). Wanita dengan hipertensi pada kehamilan dapat mengalami peningkatan respon terhadap berbagai substansi endogen (seperti prostaglandin, tromboxan) yang dapat menyebabkan vasospasme dan agregasi platelet (Winkjosastro, 2000). Penumpukan trombus dan perdarahan dapat mempengaruhi sistem saraf pusat yang ditandai dengan sakit kepala dan defisit syaraf lokal dan kejang (Winkjosastro, 2000).

Preeklamsi akan hilang saat melahirkan, sehingga bila pre eklamsi terjadi di minggu-minggu akhir kehamilan, dokter akan mengambil tindakan untuk segera mengeluarkan bayi. Tapi bila pre eklamsi terjadi di awal kehamilan, maka dokter akan berusaha memperpanjang kehamilan sampai bayi dianggap telah cukup untuk lahir ( Manuaba, 2005).

\section{METODE PENELITIAN}

Desain Penelitian adalah Eksplarantory Reserver dengan desain retrospectif. Sedangkan. Sasaran penelitian ini adalah semua pasien rawat inap yang mengalami PEB di ruang ICU RSUD Moewardi Surakarta dari awal bulan Januari tahun 2011 sampai dengan bulan Maret tahun 2012. Dalam penelitian ini penulis menggunakan uji Chi Kuadrat. Test Chi Kuadrat ini digunakan untuk menguji hipotesis bila dalam populasi terdiri dari dua kelompok kelas, datanya berbentuk nominal dan jumlah sampelnya besar ( lebih dari 25 ). Dari populasi itu akan diteliti dengan menggunakan sampel yang diambil dari populasi tersebut (Sugiyono, 2006). 
Tabel 1

\section{Pengaruh Faktor Gravida}

Responden

\begin{tabular}{llllll}
\hline \multicolumn{7}{c}{ Responden } \\
\hline & $\begin{array}{l}\text { Primigrav } \\
\text { ida }\end{array}$ & $\begin{array}{l}\text { Multigrav } \\
\text { ida }\end{array}$ & $\begin{array}{l}\text { Gravi } \\
\text { da }\end{array}$ & $\begin{array}{l}\text { Tot } \\
\text { al }\end{array}$ \\
\hline Pre & Ring & 10 & 5 & 2 & 17 \\
eklam & an & 8 & 6 & 5 & 19 \\
si & Berat & & & & \\
berat & & & & & \\
\hline Total & & 18 & 11 & 7 & 36 \\
\hline
\end{tabular}

Tabel 2

Pengaruh Faktor Distensi

Rahih Berlebih Responden

\begin{tabular}{llllll}
\hline & & Hidramnion & $\begin{array}{l}\text { Hamil } \\
\text { ganda }\end{array}$ & $\begin{array}{l}\text { Hamil } \\
\text { tunggal }\end{array}$ & Total \\
\hline $\begin{array}{l}\text { Pre } \\
\text { eklamsi } \\
\text { berat }\end{array}$ & Ringan & 11 & 1 & 5 & 17 \\
\hline Total & 6 & 5 & 8 & 19 \\
\hline
\end{tabular}

Tabel 3

Hasil Analisis Pengaruh Antara Peb Dengan Gravida

\begin{tabular}{lcccc}
\hline & & Value & Df & $\begin{array}{l}\text { Asymp. sig } \\
\text { (2-sided) }\end{array}$ \\
\hline $\begin{array}{l}\text { Pearson } \\
\text { square }\end{array}$ & Chi- & 1,492 & 2 & .474 \\
\hline
\end{tabular}

Tabel4

Kejadian PEB Dihubungkan Dengan Faktor Distensi Rahim Berlebih

\begin{tabular}{|c|c|c|c|c|}
\hline & & Value & $\mathrm{Df}$ & $\begin{array}{l}\text { Asymp. sig } \\
\text { (2-sided) }\end{array}$ \\
\hline $\begin{array}{l}\text { Pearson } \\
\text { square }\end{array}$ & Chi- & 1,492 & 2 & .474 \\
\hline
\end{tabular}
square

\section{Tabel 5}

Hasil Analisis Pengaruh Antara

Peb Dengan Penyakit Yang Menyertai Menggunakan Uji Non Parametrik Chi Square

\begin{tabular}{|c|c|c|c|c|c|}
\hline & Value & Df & $\begin{array}{l}\text { Asymp. } \\
\text { sig (2- } \\
\text { sided) }\end{array}$ & $\begin{array}{l}\text { Exact } \\
\text { sig (2- } \\
\text { sided) }\end{array}$ & $\begin{array}{l}\text { Exact } \\
\text { sig (2- } \\
\text { sided) }\end{array}$ \\
\hline $\begin{array}{l}\text { Pearson } \\
\text { Chi- } \\
\text { square }\end{array}$ & & 929 & 1 & 335 & 17 \\
\hline Total & & 17 & 6 & 13 & 36 \\
\hline
\end{tabular}

\section{PEMBAHASAN}

Menurut Prawirohardjo (2002) preeklamsi dipengaruhi oleh faktor gravida hal ini dikarenakan terjadinya patologi akibat implantasi sehingga timbul iskemia yang diikuti sindrom inflamasi, secara umum faktor gravida ada hubungannya dengan kejadian PEB. Tetapi dari penelitian yang dilakukan, diperoleh hasil $r$ hitung lebih kecil dari pada $r$ tabel sehingga Ho diterima dan Ha ditolak. Jadi dapat disimpulkan bahwa tidak ada hubungan antara kejadian PEB dengan faktor gravida pada pasien rawat inap di ruang ICU RSUD Dr. Moewardi Surakarta.

Berdasarkan penelitian yang dilakukan Rozikhan (2007) yang berjudul "Faktor-faktor risiko terjadinya preeklampsia berat di rumah sakit dr. H. soewondo Kendal", menggunakan metode studi kasus kontrol dengan mengambil data di rumah sakit Dr. H Soewondo Kendal, dimulai bulan Agustus 2004 Desember 2006. Responden yang menjadi subyek penelitian adalah kasus wanita hamil dengan preeklampsia berat dan kontrol yaitu wanita yang hamil normal. Jumlah kelompok kasus sebanyak 100 orang dan jumlah kelompok control sebanyak 100 orang. Kasus maupun control dicari faktor risikonya dengan penelusuran waktu ke belakang dan dihitung besar risiko dengan menggunakan analisis regresi logistic ganda, diperoleh hasil ada hubungan resiko antara factor gravid dengan kejadian PEB di RS Dr. H.

Menurut Winkjosastro (2000), pada kehamilan ganda, hidramnion dan mola hidatidosa terjadi keregangan otot rahim yang dapat menyebabkan iskemia uteri yang dapat meningkatkan kemungkinan pre eklamsi dan eklamsi, secara umum faktor distensi rahim berhubungan dengan kejadian PEB. Tetapi dari penelitian yang telah dilakukan diperoleh hasil $r$ hitung lebih kecil dari $r$ tabel sehingga sehingga Ho diterima dan Ha ditolak. Jadi dapat disimpulkan bahwa tidak ada hubungan antara 
kejadian PEB dengan faktor distensi rahim berlebih pada pasien rawat inap di ruang ICU RSUD Dr. Moewardi Surakarta. Hasil penelitian Dly (2011) tentang Angka Kejadian dan Karakteristik Pasien Preeklampsia Berat Berulang di Bagian Obstetri dan Ginekologi RSMH (Rumah Sakit Mohammad Hoesin) Palembang Periode Januari 2009September 2010, didapatkan hasil preeklampsia berat paling banyak terjadi pada ibu dengan hidramnion yaitu sebanyak 69 orang $(69,7 \%)$. Lalu, penelitian Utama (2008) tentang Faktor Risiko yang Berhubungan dengan Kejadian Preeklampsia Berat Pada Ibu Hamil di RSD Raden Mattaher Jambi Tahun 2007, didapatkan hasil bahwa dari 85 ibu yang mengalami kejadian preeklampsia berat terdapat $61,2 \%$ ibu dengan hidramnion, sedangkan dari 85 ibu yang tidak mengalami kejadian pre-eklampsia berat terdapat $63,5 \%$ terjadi pada kehamilan tunggal, dan berdasarkan uji chi square dinyatakan tidak terdapat hubungan bermakna antara status hidramnion dengan kejadian pre-eklampsia berat. ini berbeda dengan teori Roberts (1990) dalam Bobak, Lowdermilk \& Jensen (2005) yang menyatakan bahwa kondisi obstetri yang berkaitan dengan peningkatan massa plasenta, seperti kehamilan multipel, janin besar, hidrop janin, polihidroamnion, kehamilan mola hidatidosa membuat risiko gejala pre-eklampsia menjadi lebih tinggi. Perbedaan ini terjadi karena faktor risiko yang ada pada ibu hamil tidak selalu sama, tidak semua ibu yang mengalami preeklampsia berat datang dengan kondisi obstetri yang mengalami komplikasi, mungkin ada faktor predisposisi yang lainnya, tetapi ibu yang mengalami kondisi obstetri yang komplikasi pasti berisiko mengalami kejadian preeklampsia berat. Hal ini didukung oleh pernyataan ACOG (2002).

Menurut Manuaba (2005), Kondisi sebelum hamil seperti hipertensi kronis, diabetes, penyakit ginjal atau lupus, akan meningkatkan risiko terkena preeklamsia. Kehamilan dengan hipertensi esensial atau hipertensi yag telah ada sebelum kehamilan dapat berlangsung sampai aterm tanpa gejala mejadi pre eklamsi tidak murni. Penyakit gula atau diabetes mellitus dapat menimbulkan pre eklamsi dan eklamsi begitu pula penyakit ginjal karena dapat meingkatkan tekanan darah dan dapat menyebabkan pre eklamsi, secara umum faktor penyakit penyerta berhubungan dengan kejadian PEB. Tetapi dari penelitian yang telah dilakukan diperoleh hasil $r$ hitung lebih kecil dari $r$ tabel sehingga sehingga Ho diterima dan Ha ditolak. Jadi dapat disimpulkan bahwa tidak ada hubungan antara kejadian PEB dengan faktor penyakit penyerta pada pasien rawat inap di ruang ICU RSUD Dr. Moewardi Surakarta. Hasil penelitian ini berbeda dengan teori yang menyatakan bahwa proses penyakit penyakit pembuluh darah kolagen, penyakit pembuluh darah, penyakit ginjal, ibu yang mempunyai riwayat penyakit hipertensi, dan ibu yang pernah mengalami preeklampsia berat pada kehamilan sebelumnya dapat menjadi faktor risiko terjadinya pre-eklampsia berat (Bobak, Lowdermilk \& Jensen, 2005). Perbedaan ini terjadi mungkin karena ibu tidak pernah melakukan pemeriksaan kesehatan sebelumnya (screening penyakit) yang 
menyebabkan sang ibu tidak tahu penyakit yang dialaminya atau kecenderungan masyarakat Indonesia yang akan datang ke pelayanan kesehatan jika telah mengalami tanda dan gejala penyakit, selain itu relatif penyakit akan timbul pada usia tua, maka ketika perawat bertanya dan mencatat dalam status pasien, sang ibu mengatakan tidak memiliki salah satu di antara riwayat penyakit ginjal, jantung, diabetes mellitus, dan sebagainya (Bobak, Lowdermilk \& Jensen, 2005).

Menurut Manuaba (2005), Usia ibu merupakan salah satu faktor risiko yang berhubungan dengan kualitas kehamilan. Usia yang paling aman atau bisa dikatakan waktu reproduksi sehat adalah antara umur 20 tahun sampai umur 30 tahun. Penyulit pada kehamilan remaja salah satunya pre eklamsi lebih tinggi dibandingkan waktu reproduksi sehat. Keadaan ini disebabkab belum matangnya alat reproduksi untuk hamil, secara umum faktor usia ibu berhubungan dengan kejadian PEB. Tetapi dari penelitian yang telah dilakukan diperoleh hasil $r$ hitung lebih kecil dari $r$ tabel sehingga Ho diterima dan Ha ditolak. Jadi dapat disimpulkan bahwa tidak ada hubungan antara kejadian PEB dengan faktor usia ibu pada pasien rawat inap di ruang ICU RSUD Dr. Moewardi Surakarta. Dalam penelitian Dly (2011) tentang Angka Kejadian dan Karakteristik Pasien Pre-eklampsia Berat Berulang di Bagian Obstetri dan Ginekologi RSMH (Rumah Sakit Umum Mohammad Hoesin) Palembang Periode Januari 2009September 2010, dinyatakan bahwa usia 20-35 tahun (usia produktif) memiliki jumlah terbanyak yang menderita pre-eklampsia berat, dan diperoleh hasil tidak ada hubungan antara faktor usia ibu dengan kejadian PEB.

Menurut Winkjosastro (2000), Paritas 2 - 3 merupakan paritas paling aman ditinjau dari sudut kematian maternal. Paritas 1 dan paritas tinggi (lebih dari 3) mempunyai angka kematian maternal lebih tinggi. Lebih tinggi paritas, lebih tinggi kematian maternal, karena hal ini merupakan kelompok risiko tinggi untuk toksemia gravidarum. Kematian maternal akan meningkat tinggi jika sudah menjadi eklamsi, secara umum faktor paritas berhubungan dengan kejadian PEB. Tetapi dari penelitian yang telah dilakukan diperoleh hasil $r$ hitung lebih kecil dari $r$ tabel sehingga sehingga Ho diterima dan Ha ditolak. Jadi dapat disimpulkan bahwa tidak ada hubungan antara kejadian PEB dengan faktor paritas pada pasien rawat inap di ruang ICU RSUD Dr. Moewardi Surakarta

\section{KESIMPULAN DAN SARAN}

Tidak ada pengaruh hubungan antara kejadian PEB dengan : faktor gravid, distensi rahim berlebih, penyakit penyerta, faktor usia, faktor paritas. Penulis. Bagi penelitian yang serupa diharapkan dapat melakukan penelitian yang lebih kompleks dan luas Variabel maupun jumlah sampelnya, serta lebih berhati - hati dan lebih teliti dalam menentukan sample yang akan diambil sebagai responden dan pemilihan metodologi yang tepat agar nanti hasilnya dapat signifikan dengan teori yang ada. 


\section{DAFTAR RUJUKAN}

Anonim. 2004. Buku Ajar keperawatan Maternitas. Edisi 4. Jakarta: Yayasan Bina Pustaka

Anonim. 2005. Journalis Sensus Indonesia dan Dunia. Jakarta: Yayasan BinaPutaka

Arikunto, Suharsimi. 2006. Prosedur Penelitian Pendekatan Praktek. Jakarta: Rineka Cipta

Chapman, Stephen, J. 1999. Elektric Mechinery Fundamentals. Singapore: Nill Book Company Cunniagham. 2003. Obstetri Williem. Jakarta: ECG

Helen, Farier. 2009. Ilmu Kebidanan. Edisi 3. Jakarta: Yayasan Bina Pustaka Manuaba. 2005. Ilmu Kebidanan Penyakit Kandungan dan KB. Jakarta: ECG

Mansjoer, Arif. 2000. Kapita Selekta Kedokteran. Jakarta: Media

Michael. 2005. Keperawatan Maternitas. Jakarta: ECG Nelson. 2003. Keperawatn Maternitas. Jakarta: ECG
Nikita, A, Vizniak. 2006. Buku Ajar Keperawatan Maternitas. Jakarta:ECG

Notoatmodjo. 2002. Metodologi Penelitian Kesehatan. Jakarta: Rineka Cipta

Prawiro, Harjo. 2002. Buku Panduan Praktis Pelayanan Kesehatan Maternal Neonatal. Jakarta: Yayasan Bina Pustaka

Priyanto, Dwi. 2008. Mandiri Belajar SPSS. Yogyakarta. Media kom

Rustam, Mochtar. 2002. Buku Ajar Keperawatan Maternitas. Jakarta: ECG

Sugiyono. 2006 Statistik Untuk Penelitian. Bandung: Alfa Beta Sugiyono. 2011. Statistik Untuk Penelitian. Bandung: Alfa Beta

Syakib, Bakri. 1997. Kesehatan Preeklamsi dan Eklamsi. Jakarta: ECG

Trijatmo, R. 2005. Ilmu Kandungan. Jakarta: Yayasan Bina Pustaka

Winkjosastro, Hanifa. 2000. Ilmu Kandungan. Edisi 2. Jakarta: Yayasan Bina Pustaka 